\title{
Characterization of Excretory and Secretory Larval Antigen of Toxocara canis by Western Blotting
}

\author{
K.T. Kavitha ${ }^{2 *}$, C. Sreekumar ${ }^{1}$, B.R. Latha ${ }^{2}$, A. Mangala Gowri ${ }^{3}$ and B. Nagarajan ${ }^{4}$ \\ ${ }^{1}$ Department of Wildlife Science, Madras Veterinary College, Chennai 600 007, India \\ ${ }^{2}$ Department of Veterinary Parasitology, Madras Veterinary College, Chennai 600 007, India \\ ${ }^{3}$ Stem Cell Research and Regenerative Medicine, Madras Veterinary College, \\ Chennai 600 007, India \\ ${ }^{4}$ Department of Veterinary Preventive Medicine, Madras Veterinary College, \\ Chennai 600 007, India \\ *Corresponding author
}

\begin{tabular}{|c|c|}
\hline & A B S T R A C T \\
\hline $\begin{array}{l}\text { Ke y w o r d s } \\
\text { Toxocara canis, } \\
\text { Excretory-secretory } \\
\text { larval antigens, } \\
\text { Western blotting }\end{array}$ & \multirow{3}{*}{$\begin{array}{l}\text { Toxocara canis is a dog helminth which causes visceral larva migrans (VLM) in humans. } \\
\text { The identification of specific antigens of } T \text {. canis is important in order to develop better } \\
\text { diagnostic techniques. The excretory-secretory larval antigens of } T \text {. canis (ESLA) were } \\
\text { prepared by in vitro culturing of T. canis larvae in RPMI } 1640 \text { medium. These antigens } \\
\text { were separated using sodium dodecyl sulphate-poly acrylamide gel electrophoresis (SDS- } \\
\text { PAGE) which revealed } 9 \text { protein bands at a molecular weight of } 17,18,22,24,26,28,30 \text {, } \\
32 \text { and } 120 \mathrm{kDa} \text {. The immuno reactivity of excretory-secretory larval antigens of } T \text {. canis } \\
\text { was checked by Western blotting using hyper immune serum raised in rabbits against } \\
\text { ESLA antigen which showed six immuno reactive bands at a molecular weight of } 17,18 \text {, } \\
22,24,30 \text { and } 32 \mathrm{kDa} \text {. These antigens merit further evaluation as candidate for use in } \\
\text { diagnosis of toxocariasis in humans and adult dogs. }\end{array}$} \\
\hline Article Info & \\
\hline $\begin{array}{l}\text { Accepted: } \\
\text { 10 April } 2019 \\
\text { Available Online: } \\
10 \text { May } 2019\end{array}$ & \\
\hline
\end{tabular}

\section{Introduction}

Human toxocariasis is a major parasitic zoonosis, caused by infection with the larvae of Toxocara canis, the common roundworm of dogs and less frequently, of Toxocara cati, the roundworm of cats (Despommier, 2003). Humans, especially young childrens are more susceptible because of their habits of geophagy, onchophagy, poor hygienic conditions and their larger risk of exposure to soil contaminated with parasitic eggs (Smith et al., 2009). Toxocara cannot complete its life cycle in humans and parasite development is arrested at the larval stage. The migrating larvae give rise to the clinical syndromes of visceral larva migrans (VLM), ocular toxocariasis (OT) and a non-symptomatic infection covert toxocariasis (CT) (Magnaval et al., 2001).

The diagnosis of human toxocariasis currently depends on immunological examinations because it is extremely difficult to detect an 
infective Toxocara larva in biopsy samples. In immunological tests, the excretory-secretory antigens of $T$. canis larvae (TES) are widely used for both the diagnosis and seroepidemiological studies (Smith et al., 2009).

These antigens are obtained from in vitro maintenance of infective larvae and are a mixture of highly immunogenic glycoproteins (Maizels et al., 1993). Since the first description of TES antigen production (De Savigny, 1975), few modifications in the method had been reported by many researches to increasing the parasite yield up to five fold, improving the larval purity and reducing the execution time of the protocol (PonceMacotela et al., 2011; Thomas et al., 2016). Recently number of diagnostic candidates has been investigated like Toxocara excretorysecretory antigen (TES-57) and recombinant Toxocara excretory-secretory antigens (rTES120, rTES-26, TES-30USM) (Suharni et al., 2009).

Therefore this paper includes an improved protocol for obtaining $T$. canis larvae, isolation of excretory-secretory (ES) antigen and characterization of antigenic components present in the larval excretory and secretory antigen of $T$. canis.

\section{Materials and Methods}

\section{Parasite}

Adult Toxocara canis worms were collected from naturally infected puppies kept at Blue cross of India, Tamil Nadu, after deworming with Piperazine hydrate (Virbac, India) at the dose rate of $100 \mathrm{mg} / \mathrm{kg}$ orally. The eggs were isolated from adult female worms following hysterectomy (Thomas et al., 2016). The eggs were incubated in 2 per cent formal saline at room temperature $\left(\sim 26^{\circ} \mathrm{C}\right)$ for 28 days to induce embryonation.

\section{Excretory and secretory larval antigen production}

The embryonated eggs were repeatedly washed with sterile phosphate buffered saline (PBS), $\mathrm{pH} 7.2$ to remove the formalin. Subsequently the eggs were treated with 6 per cent sodium hypochlorite for $5 \mathrm{~min}$ at room temperature to lyses the chitin-protein layer (Schonardie et al., 2014). The eggs were washed again with PBS to remove the sodium hypochlorite. Hatching was induced by incubating decorticated eggs for overnight at $37^{\circ} \mathrm{C}$ in RPMI 1640 medium with glutamine and sodium bicarbonate. The hatched larvae were filtered through a polystyrene membrane with a $20 \mu \mathrm{m}$ pore size.

The live larvae were transferred to RPMI 1640 medium supplemented with L-glutamine and sodium bicarbonate (Sigma-Aldrich Co, USA) containing antibiotics and antifungal solution (100 U/ml Penicillin-G, $100 \mu \mathrm{g} / \mathrm{ml}$ Streptomycin and $25 \mu \mathrm{g} / \mathrm{ml}$ Amphotericin B) in the $\mathrm{T}_{25}$ tissue culture flask at a concentration $10^{3}$ larvae/ml and kept at $37^{\circ} \mathrm{C}$ in 5 per cent $\mathrm{CO}_{2}$ incubator. The culture supernatant was removed 5 days interval, pooled and centrifuged to precipitate all debris.

The resulting supernatant was filtered through a $0.22 \mu \mathrm{m}$ syringe filter (Millipore, USA) and stored at $-20^{\circ} \mathrm{C}$ with $1 \mathrm{mM}$ phenyl methyl sulfonyl fluoride (PMSF). The stored ES antigen was then mixed, dialyzed (molecular weight cutoff $10 \mathrm{kDa}$, Sigma-Aldrich $\mathrm{Co}$, USA) against PBS, $\mathrm{pH} 7.2$ for $12 \mathrm{~h}$ at $4^{\circ} \mathrm{C}$ and then concentrated to one tenth of initial volume using polyethylene glycol (PEG 6000-Himedia, India) at $4^{\circ} \mathrm{C}$. The protein concentration of resultant ESLA antigen was determined by bicinchoninic acid (BCA) kit (Genei, Bangalore) method. The ESLA was stored in aliquots at $-20^{\circ} \mathrm{C}$. 


\section{Characterization of ESLA antigen}

\section{SDS-PAGE analysis}

The protein fractions of the ESLA antigen of $T$. canis were separated by polyacrylamide gel electrophoresis in the presence of sodium dodecyl sulphate (SDS-PAGE) using discontinuous system in a Mini-PROTEAN II Electrophoresis unit (Bio-Rad, USA). The antigen $(20 \mu \mathrm{g} / \mathrm{lane})$ was diluted in $2 \mathrm{X}$ concentrate Laemmli sample buffer and boiled for 5 minutes to denature the protein then loaded in the $12 \%$ polyacrylamide gel. A standard prestained molecular weight marker (MW 10 to $250 \mathrm{kDa}$, Bio-Rad) was used for calibrating the gel.

The electrophoresis was performed at a constant voltage of $100 \mathrm{~V}$ till the tracking dye reaches $1 \mathrm{~cm}$ above the lower extremity. The gel was subjected to staining with $0.1 \%$ Coomassie Brilliant Blue R 250 (Sigma, B0149) overnight followed by destaining. The gel was photographed with gel documentation system (Bio-Rad Gel Documentation system $\mathrm{XR}+$ with Image Lab software version 3.0, USA).

\section{Identification of immunogenic fractions}

\section{Raising of hyper immune serum}

Two adult, New Zealand white rabbits of either sex aged about one year old were maintained as per CPCSEA guidelines (Approved Protocol No. 2345/16/DFBS dated. 26.10.2016). The rabbits were immunized with $0.5 \mathrm{mg}$ of ESLA antigen with equal volume of Montanide (Seppic) adjuvant on 0 day intra muscularly. The booster doses were given on 14 and 28 days after primary immunization with same antigen. The rabbits were bled by ear vein 10 days after the last injection and serum was separated and preserved at $-20^{\circ} \mathrm{C}$.

\section{Western blotting}

The immunogenic fractions were identified by Western blot analysis according to the method described by Towbin et al., (1979). Following electrophoresis, the proteins were transferred to nitrocellulose membrane (Sigma, USA) having a pore size of $0.45 \mu \mathrm{m}$ by semidry blotting apparatus (Bio-Rad, USA) at $25 \mathrm{~V}$ for one hour. The prestained protein marker carrying nitrocellulose membrane was cut separately. The rest of the nitrocellulose membrane was incubated in 5 per cent skim milk powder overnight at $4^{\circ} \mathrm{C}$. The membrane was washed in washing buffer thrice, each for 5 minutes. The nitrocellulose membrane was incubated in hyper immune serum at a dilution of $1: 100$ in PBS for 1 hour at $37^{\circ} \mathrm{C}$, washed in washing buffer thrice each for 5 minutes. The membrane was incubated with anti-Rabbit-IgG Horse Radish Peroxidase (HRP) conjugate (Sigma, USA) 1:1000 dilution for 1 hour at $37^{\circ} \mathrm{C}$, washed in PBST three times and then substrate Diamino benzidine (DAB) solution was added. When brown colour bands appeared, the reaction was stopped by decanting the substrate solution and replacing it with distilled water. Thereafter, the membrane was allowed to dry.

\section{Results and Discussion}

To carryout studies aimed to improving the diagnosis of VLM, an important first step is to obtain sufficient quantities of ESLA. We modified few steps in the standard protocol for obtaining ESLA producing T. canis larvae to improve larval yield, purity and shorten the duration of procedures. On an average, about 90,000 eggs were isolated from each adult female worm of $T$. canis (Fig. 1). Embryonation of $62 \%$ of the eggs were observed after 7 days of cultivation while after 28 days of incubation the frequency of embryonation reached up to $80 \%$ (Fig. 2). 
The embryonated eggs with second stage larvae were washed and decorticated using 6 per cent sodium hypochlorite solution. It was found that after 5 minutes of incubation with sodium hypochlorite solution the chitinprotein layer of the eggs got dissolved to a thin membrane around the larvae (Fig. 3). Decortication of larvated eggs using different concentrations of sodium hypochlorite was tried elsewhere (Roldan et al., 2006, PonceMacotela et al., 2011 and Thomas et al., 2016). Hatching was induced by incubating the eggs with RPMI 1640 medium overnight at $37^{\circ} \mathrm{C}$ in an incubator. The hatched larvae were filtered through a polystyrene membrane with a $20 \mu \mathrm{m}$ pore size. About 70 per cent of the viable larvae were recovered by this method (Fig. 4). Hatched larvae were cultured in RPMI-1640 medium containing antibiotics at a concentration of $10^{3}$ larvae/ml with replacement of medium at 5 days interval and maintained up to 2 months (Fig. 5). The protein concentration of ESLA was obtained $2.5 \mathrm{mg} / \mathrm{ml}$ of antigen.

In the present study, the excretory secretory larval antigens (ESLA) of $T$. canis were characterized by SDS-PAGE using 12\% gel and stained with coomassie brilliant blue which revealed 9 protein bands with a molecular weight of 17, 18, 24, 26, 28, 30, 32 and $120 \mathrm{kDa}$ (Fig. 6). Colli et al., (2011) reported that the SDS-PAGE profile (10 per cent) of larval ES antigen of $T$. canis when stained with silver stain showed at molecular weight of 105-120, 70, 55, 44 and 31-34 kDa protein bands.

Fig.1 Unembryonated eggs teased from the uterus of Toxocara canis worms

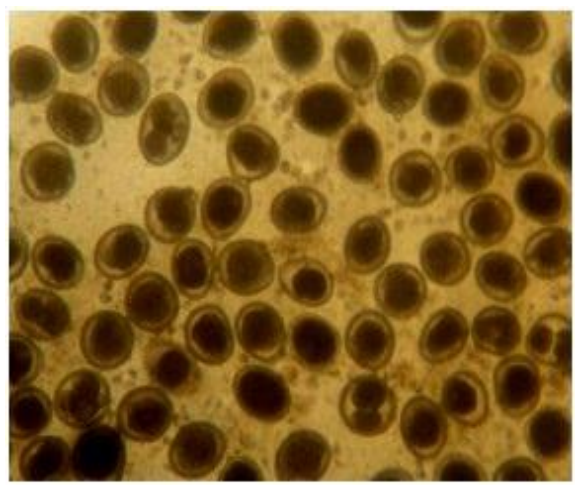

Fig.2 Embryonated eggs in 2\% formal saline containing second stage larvae

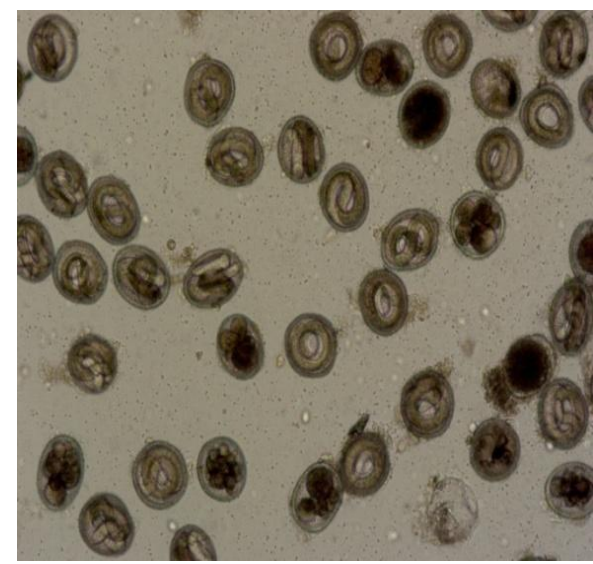


Fig.3 Decorticated eggs of T. canis using 6\% sodium hypochlorite

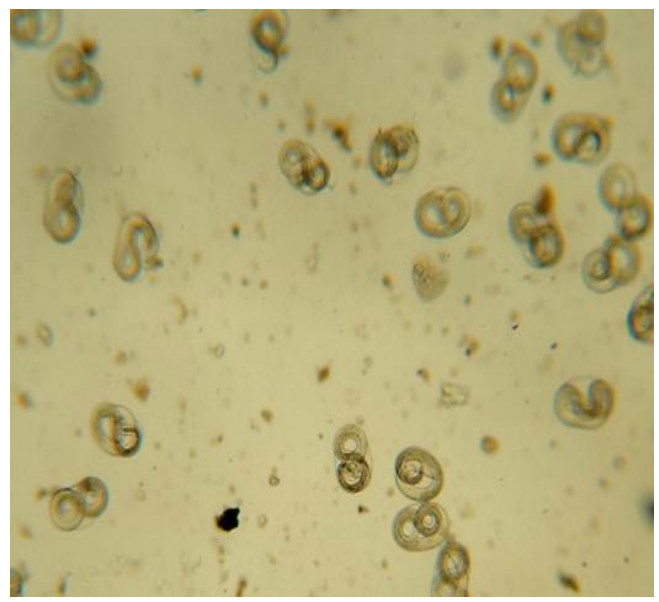

Fig.4 Hatched out second stage larvae of T. canis

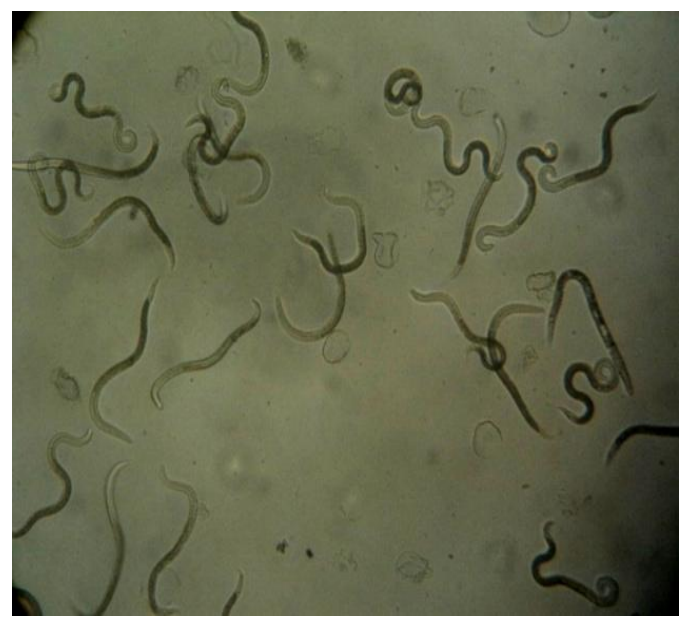

Fig.5 Larvae cultivated in RPMI 1640 medium

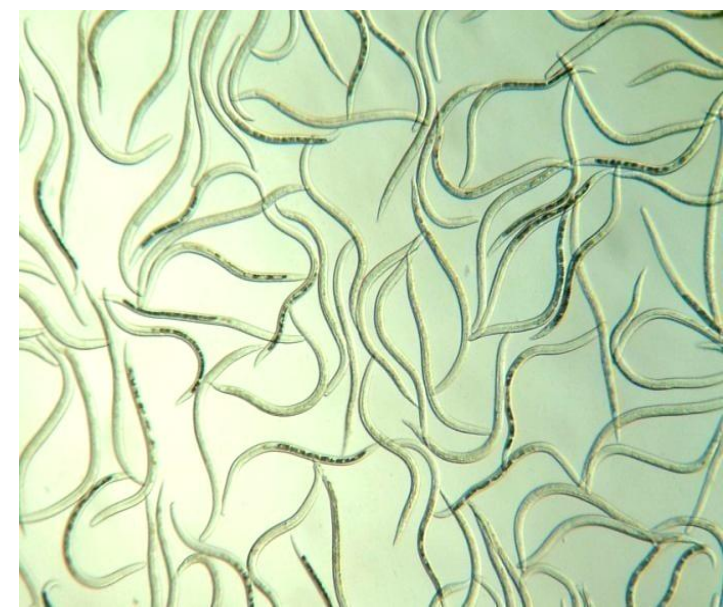


Fig.6 SDS - PAGE profile of ESLA antigen of Toxocara canis stained with Coomassie blue stain

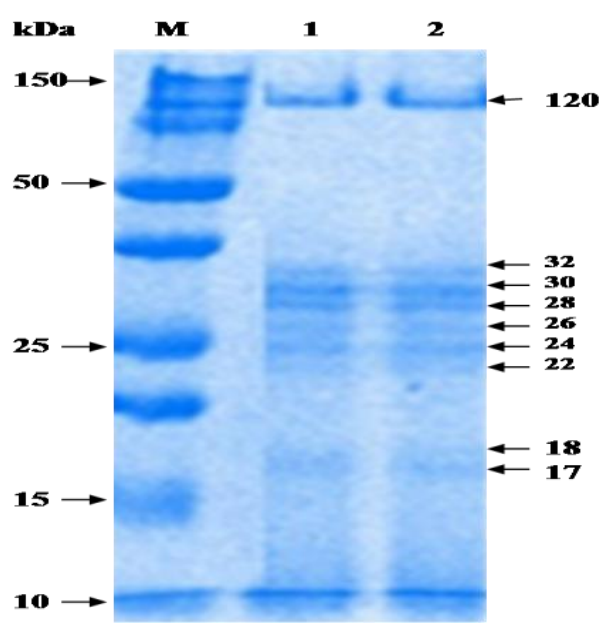

Fig.7 Western blot studies of ESLA antigen using hyperimmune sera raised in rabbits

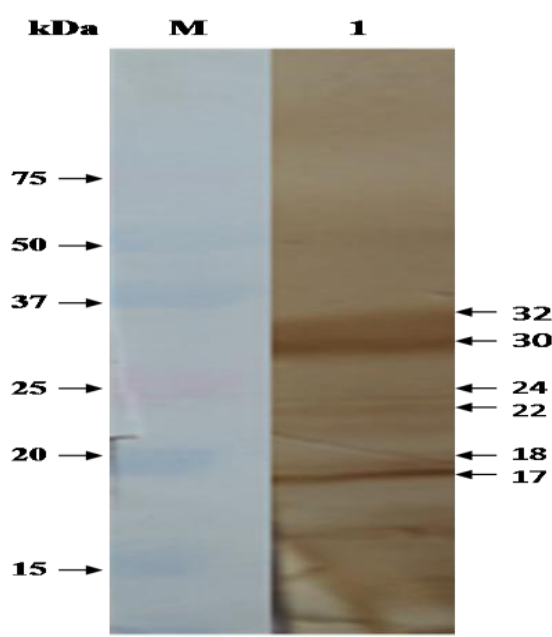

Protein bands of larval ES antigen of T. canis recovered in this study appear similar in molecular weight to those associated with larval ES antigen of $T$. canis reported by Colli et al (2011) at mol. wt. of 120 (105-120), 32 (31-34) kDa. SDS-PAGE of T. canis ES has produced variable results between laboratories. Sugane and Oshima (1983) described a single band at $35 \mathrm{kDa}$, while Maizels et al., (1984) demonstrated 5 major components (ES labelled with radioiodination) at 32, 55, 70, 120 and $400 \mathrm{kDa}$. Meghji and Maizels (1986), carrying out extensive molecular and biochemical characterization of ES from long-term cultures, using labelled ES, concluded that there were a number of macromolecules secreted, of which the major components were glycoproteins that differed in essential characteristics, i.e., 32, 120 and $400 \mathrm{kDa}$.

The immuno reactivity of ESLA antigens of $T$. canis was checked by Western blotting using hyper immune serum raised in rabbits which revealed six immuno reactive bands at a molecular weight of 17, 18, 22, 24, 30 and 
32 kDa (Fig. 7). Present study shows T. canis excretory-secretory proteins from larvae, which similar to those found in the crude antigen of $T$. canis larval protein bands at 28, 30 and $120 \mathrm{kDa}$ (Jin et al., 2013) and also relate to those found in the ES antigen of adult $T$. canis at molecular weight band of 30 kDa (Sudhakar et al., (2014). The differences in the banding pattern can be attributed to differences in the preparation of antigen, age of larval culture (Iddawela et al., 2007), contamination with somatic antigens in culture due to dead larvae, variation in the running condition of gel (Roldan and Espinoza, 2009) and variation due to larval strain differences (Badley et al., 1987). These antigens merit further evaluation as candidate for use in diagnosis of toxocariasis in humans and adult dogs.

\section{References}

Badley, J.E., Grieve R.B., Bowman, D.D., Glickman, L.T. and Rockey, J.H. (1987). Analysis of Toxocara canis larval excretory-secretory antigens: Physicochemical characterization and antibody recognition. J. Parasitol., 73: 593-600.

Colli, C., Rubinsky-Elefant, G., Paludo, M., Falavigna, D. and Guilherme, E. (2011). An alternate technique for isolation of Toxocara canis excretory secretory antigens. Brazilian Journal of Pharmaceutical Sciences, 47: 119123.

De Savigny, D.H., (1975). In vitro maintenance of Toxocara canis larvae and a simple method for the production of Toxocara ES antigen for use in serodiagnostic tests for visceral larva migrans. J. Parasitol., 61: 781782.

Despommier, D., (2003). Toxocariasis: clinical aspects, epidemiology, medical ecology and molecular aspects. Clin. Microbiol. Rev., 16: 265-272

Iddawela, R., Rajapakse, R., Perera, N. and Agatsuma, T. (2007). Characterization of Toxocara canis species specific excretory secretory antigen (TcES-57) and development of a double sandwich ELISA for diagnosis of visceral larva migrans. Kor. J. Parasitol., 1: 19-26.

Jin, Y., Shen, C., Huh, S., Sohn, M.H., Choi, W.M. and Hong, S.T. (2013). Serodiagnosis of toxocariasis by ELISA using crude antigen of Toxocara canis larvae. Korean $J$. Parasitol., 51:433-9.

Magnaval, J.F., Glickman, L.T., Dorchies, P. and Morassin, B. (2001). Highlights of human toxocariasis. Korean Journal of Parasitology, 39:1-11.

Maizels, R.M., De Savigny, D. and Ogilvie, B.M. (1984). Characterization of surface and excretory-secretory antigens of Toxocara canis infective larvae. Parasite Immunol., 6(1):23-37.

Maizels, R.M., Gems, D.H., and Page, A.P. (1993). Synthesis and secretion of TES antigens from Toxocara canis infective larvae. In: Toxocara and toxocariasis. Clinical, epidemiological and molecular perspectives, eds. Lewis, J.W. and Maizels, R.M. pp. 141-150. London: British Society for Parasitology.

Meghji, M., and Maizels R.M. (1986). Biochemical properties of larval excretory-secretory glycoproteins of the parasitic nematode. Toxocara canis. Mol. Biochem. Parasit., 18: 155-170.

Ponce-Macotela, M., Rodríguez-Caballero, A., Peralta-Abarca, G.E., MartínezGordillo, M.N. (2011). A simplified method for hatching and isolating Toxocara canis larvae to facilitate excretory-secretory antigen collection 
in vitro. Veterinary Parasitology, 175:382-385.

Roldán, W., Cornejo, W. and Espinoza, Y. 2006. Evaluation of the dot enzymelinked immunosorbent assay in comparison with standard ELISA for the immunodiagnosis of human toxocariasis. Mem. Inst. Oswaldo Cruz, 101: 71-74.

Roldán, W.H., and Espinoza, Y.A. (2009). Evaluation of an enzyme-linked immunoelectrotransfer blot test for the confirmatory serodiagnosis of human toxocariasis. Memórias do Instituto Oswaldo Cruz, 104: 411-418.

Smith, H.V., Holland, C., Taylor, M., Magnaval, J.F., Schantz, P., and Maizels, R. (2009). How common is human toxocariasis? Towards standardizing our knowledge. Trends Parasitol., 25: 182-188.

Sudhakar, N.R., Samanta, S., Sahu, S., Raina, O.K., Gupta, S.C., Goswami, T.K., Lokesh, K.M., and Kumar, A. (2014). Characterization of excretory secretory antigens of adult Toxocara canis by Western blotting. J. Parasit. Dis., 38(2):166-169.

Sugane, K., and Oshima, T. (1983). Purification and characterization of excretory antigens of Toxocara canis larvae. Immunology, 50:113-120.

Suharni, M., Norhaida, C. A., and Noordin, R. (2009). Development and evaluation of a sensitive and specific assay for diagnosis of human toxocariasis by use of three recombinant antigens (TES-26, TES-30USM, and TES120). J. Clin Microbiol., 47: 17121717.

Thomas, D., Jeyathilakan, N., Abdul Basith, S., and Senthilkumar, T. M. A. (2016). In vitro production of Toxocara canis excretory-secretory (TES) antigen. $J$. Parasit. Dis., 40(3): 1038-1043.

Towbin, H., Yaehelin, T., and Gordon, J. (1979). Electrophoretic transfer of proteins from polyacrylamide gels to nitrocellulose sheets: procedure and some applications. Proc Natl Acad Sci, 76: 4350-4354.

\section{How to cite this article:}

Kavitha, K.T., C. Sreekumar, B.R. Latha, A. Mangala Gowri and Nagarajan, B. 2019. Characterization of Excretory and Secretory Larval Antigen of Toxocara canis by Western Blotting. Int.J.Curr.Microbiol.App.Sci. 8(05): 804-811. doi: https://doi.org/10.20546/ijcmas.2019.805.095 